\title{
POLÍTICAS PÚBLICAS NO BRASIL PARA UM TURISMO RESPONSÁVEL
}

PUBLIC POLICIES IN BRAZIL FOR RESPONSIBLE TOURISM

POLÍTICAS PÚBLICAS EN BRASIL PARA UN TURISMO RESPONSABLE

Ricardo Lanzarini

ricardolanzarini@gmail.com Pós-doutor em Lazer e Turismo (USP), Doutor em Ciências Humanas (UFSC), Mestre em Geografia (UFMS) Bacharel em Turismo (UFMS).

Margarita Barretto barretto.margarita@gmail.com Pós-doutora em Antropologia Social (UFSC), Doutora em Educação (UNICAMP), Mestre em Educação (UNICAMP) Bacharel em Turismo (PUC-CAMPINAS).

Data de submissão: 04/06/2013 Data de aprovação: 23/04/2014 
Resumo: Este texto faz um retrospecto das políticas públicas de turismo no Brasil com o objetivo de ampliar o debate e tecer considerações sobre a necessidade de políticas comprometidas com o planejamento responsável do turismo. Trata-se de uma pesquisa bibliográfica e documental que começa com a definição de políticas públicas para turismo desde os primeiros estudos em nível internacional no final do século XX e contempla o estado da arte do tema no país. Como resultado, observam-se falhas e descontinuidades dos planos de governo, que comprometem as estruturas econômicas e sociais que sustentam a formação e a reprodução dos espaços turísticos no Brasil. É um trabalho original na medida em que não é um estudo de caso, mas uma abordagem teórica que pretende fundamentar ações futuras. Espera-se que possa ter utilidade para o setor público encarregado da elaboração de políticas e do planejamento de turismo.

Palavras-chave: Turismo. Políticas públicas. Planejamento responsável.

Abstract: This text takes a historical look at public policies on tourism in Brazil, aiming to enhance the debate on and make considerations about the need for policies committed to responsible tourism planning. It is a bibliographic and documental research; it begins with a definition of tourism public policy when it was first addressed in international studies at the end of XX century, and encompasses the state of the art in Brazilian studies. As a result, failures and discontinuities were found in government plans, which challenge economic and social structures, sustaining the production and reproduction of tourism spaces in Brazil. It is original because it is not a case study, but a theoretical approach that seeks to form the basis of actions in the future. It is expected that public sectors 
in charge of tourism planning policies can make good use of it.

Keywords: Tourism. Public policies. Responsible planning.

Resumen: En este artículo se presenta una retrospectiva de las políticas públicas de turismo en Brasil con el objetivo de ampliar el debate y hacer algunas consideraciones sobre la necesidad de políticas comprometidas con el planeamiento responsable del turismo. Se trata de una investigación bibliográfica y documental que comienza por la definición de políticas públicas para el turismo a partir de los primeros estudios internacionales llevados a cabo a fines del siglo XX, llegando al estado del arte del tema en el país. Como resultado, se observan fallas y discontinuidades de los planes del sector gubernamental, que comprometen las estructuras económicas y sociales que sostienen la formación y reproducción de los espacios turísticos en Brasil. La originalidad del trabajo reside en no ser un estudio de caso sino una aproximación teórica que pretende fundamentar acciones futuras. Se espera que pueda ser útil al sector público encargado de la elaboración de políticas de planificación de turismo.

Palabras clave: Turismo. Políticas Públicas. Planificación responsable.

\section{PRIMEIRAS CONSIDERAÇÕES}

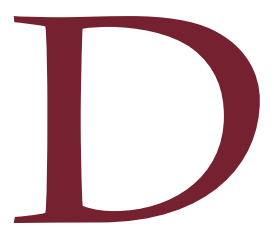

esde que começaram a ser realizados estudos e publicações sobre turismo, o papel das políticas públicas para o fenômeno e sua relação com a sociedade tem sido abordado. A fim de ampliarmos a reflexão e o debate sobre as políticas públicas e seu papel de responsabilidade com a construção/organização do setor turístico no Brasil, a partir de uma pesquisa bibliográfica e documental (LAKATOS; MARCONI, 2009), 
buscamos nas definições de políticas públicas para turismo, que despontam em nível internacional no final do século $X X$, a compreensão dos acertos e das falhas conceituais que induzem o entendimento de seu processo de formação e implementação, fato que tem ocorrido historicamente de modo falho, com pouca eficiência na prática. Foram analisados livros editados no Brasil e no exterior que ofereceram o marco teórico sobre políticas públicas em geral e políticas públicas de turismo em particular. Foram consultados artigos científicos para averiguar o estado da arte da discussão no Brasil e foram analisados documentos do planejamento de turismo no Brasil para constatar as ações desenvolvidas ao longo da história desta atividade no país.

Uma apresentação exaustiva sobre as políticas públicas de turismo pode ser encontrada em Fávero (2006), que elenca a visão dos autores clássicos internacionais e nacionais sobre o que estas são e devem ser. Também apresenta o pensamento de diferentes autores sobre qual deve ser o papel do estado no planejamento de turismo, assim como exemplos em nível internacional, mostrando a diversidade de concepções e práticas sobre este assunto. Apresenta o caso de Garibaldi/RS, no Sul do Brasil, onde uma política de turismo do Poder Público foi implementada a partir de 2001, que se reflete no sucesso internacional não apenas desta cidade, mas também de todo o Vale dos Vinhedos/RS, onde está localizada.

Lickorish (1996) define a política de turismo como um conjunto de documentos que estabelecem objetivos para serem atingidos mediante ações de planejamento, em função de uma série de alternativas. Implica escolher onde e como aplicar recursos, que podem ser escassos.

Divide o planejamento em várias etapas: determinação de objetivos; elaboração de uma política tendo como base esses objetivos; elaboração de diretrizes políticas para o planejamento e programas de implementação. No entanto, reconhece que muitos países não têm políticas explícitas a priori, estas vão sendo criadas no decorrer das ações de planejamento.

Na segunda metade do século XX, a política era quase sempre elaborada em nível governamental, mas, crescentemente, conta com a participação do setor privado em países desenvolvidos. Nos países onde ainda o papel do governo é predominante, sua função é dar aprovação sobre o tipo de objetivos a serem 
colocados na política, que se transforma em marco de referência para as ações de planejamento.

Seja qual for o encarregado de elaborar as políticas de turismo, estas - como toda política pública - sempre estarão atreladas ao projeto ideológico de quem tem o poder de decisão ${ }^{1}$.

Para a formulação de uma política de turismo, diz Lickorish (1999) que são necessários objetivos que devem estar relacionados aos objetivos de desenvolvimento nacional (ou regional), desde que o setor turismo é apenas um de vários. Os objetivos de uma política de turismo também variam de país para país em função das necessidades. Para alguns países, o mais importante é a entrada de divisas, para outros, a geração de empregos. A política determina que tipo de produto turístico pode ser oferecido e que produto deve ser oferecido, em função de questões culturais, religiosas, de infraestrutura, de meio ambiente; quais tipos de turistas devem ser atraídos, de que forma o turismo deve ser comercializado; quem deve conduzir os negócios turísticos, se a empresa é pública ou privada, ou uma associação de ambas, se deve ser privilegiado o turismo nacional ou o estrangeiro, se o turismo será planejado em enclaves ou será integrado na sociedade, se os estrangeiros poderão ter terras e investimentos, se haverá capacitação da mão de obra nacional ou se esta será importada.

Lickorish também expressa que, para elaborar a política de turismo, os possíveis efeitos em longo prazo deverão ser previstos.

Cooper et al. (2001) defendem a necessidade de haver políticas públicas de turismo pelo fato de o planejamento do turismo não depender apenas deste setor da economia e porque seus efeitos também o extrapolam, atingindo a população em geral. Se bem que as políticas públicas são atribuição do Poder Público, há muitas ações do governo que não são necessariamente políticas públicas, como, por exemplo, marketing de turismo, controle de uso da terra ou regulação de mercado.

Goeldner, Brent Ritchie e McIntosh (2002, p. 294) definem política de turismo como: 
Um conjunto de regulamentações, regras, diretrizes, diretivas, objetivos e estratégias de desenvolvimento e promoção que fornece uma estrutura na qual são tomadas as decisões coletivas e individuais que afetam diretamente o desenvolvimento turístico e as atividades diárias dentro de uma destinação.

Acrescentam que o propósito de uma política de turismo é propiciar o máximo de benefícios aos interessados e minimizar os prejuízos, uma vez que a opção por promover turismo numa determinada localidade [região ou país] traz consequências positivas na elevação da renda, na geração de empregos e na entrada de divisas, porém pode trazer [e historicamente traz] consequências negativas para o meio ambiente natural e cultural que podem também afetar os turistas na medida em que sua experiência pode ficar comprometida.

Uma política de turismo tem que contemplar os diversos grupos de residentes, entre os quais estão os relacionados ao trade turístico e os que não, assim como os visitantes. O papel das políticas de turismo deve ser o de definir os termos do funcionamento do turismo, dar uma direção e uma orientação comum para todos os interessados no setor, facilitar o consenso de estratégias e objetivos para uma destinação turística, fornecer uma estrutura para discussões públicas sobre o papel de cada grupo de atores sociais involucrados e permitir que o turismo estabeleça de forma efetiva interfaces com outros setores da economia (GOELDNER; BRENT; RITCHIE; MCINTOSH, 2002, p. 295). Para os autores, uma política nacional de turismo deverá tratar do papel do turismo dentro do desenvolvimento geral, do tipo de destinação que irá cumprir de forma mais eficaz as funções desejadas ou necessárias, dos tipos e níveis de taxação, do financiamento para o setor [quem financiará e com que prazos], acessos e infraestrutura, práticas regulatórias de comercialização por parte de agências, operadoras e transportadoras, práticas ambientais, relacionamento com a comunidade residente, oferta de recursos humanos, legislação trabalhista, tecnologia, marketing e funcionamento do turismo estrangeiro. Os autores elencam como principais componentes de uma política turística a política de recursos físicos, a de recursos humanos, a de recursos financeiros, a de recursos de informação e a de recursos de programas e atividades; também política de preços e de distribuição. 
Deve-se acrescentar a necessidade de articulação com outros setores para acompanhar o desenvolvimento do turismo; com políticas de saúde, de saneamento básico e de educação, para proporcionar uma boa qualidade de atendimento; políticas fiscais, trabalhistas e distributivas para garantir que 0 turismo seja um verdadeiro vetor de desenvolvimento e proporcione de fato o efeito multiplicador desejado, e políticas de uso do solo para garantir a preservação do meio ambiente para todos.

De acordo com Goeldner, Brent Ritchie e MacIntosh (2002), as partes interessadas no turismo são os residentes, os governos [municipais, regionais e/ ou nacionais], os grupos ambientalistas, os visitantes, os fornecedores de serviços turísticos [transporte, alojamento, etc.] os grupos culturais e os grupos sociais.

Um caso que pode ser considerado paradigmático na integração e/ou divisão de responsabilidades sobre a elaboração e a implementação de políticas de turismo é o da Nova Zelândia, onde trinta diferentes agentes governamentais têm participação no processo, entre eles: o Escritório de Esportes e Turismo, o Ministério do Interior, o Departamento de Conservação, o Ministério do Meio Ambiente, o trust de sítios históricos, o Departamento de Caça e Pesca, o Ministério da Agricultura, o Ministério de Relações Exteriores, o Ministério de Comércio, o Escritório de Desenvolvimento de Negócios, o Ministério da Saúde, o Departamento de Trabalho, a polícia de Nova Zelândia, o Ministério dos Transportes, o Departamento de Trânsito, o serviço de alfândega, o Departamento de Imigração, o Ministério da Pesca, o Departamento de Estatística, a Fundação de Ciência e Tecnologia e, em nível regional e local, as autoridades territoriais correspondentes (HALL, 2000, p. 145-151).

A política de turismo às vezes pode também ser entendida como a busca, por parte do estado, de um consenso entre os diferentes grupos de interesse que atuam tanto na administração quanto no financiamento do turismo (KERR; BARON; WOOD, 2001). É a área de atuação do Poder Público em seus diferentes níveis, do internacional ao local, de acordo com as leis correspondentes e que pode ir mudando ao longo do tempo para adaptar-se às novas circunstâncias, incluindo novos enfoques, como, por exemplo, nos últimos anos, as políticas relacionadas à conservação da natureza (TORRES DELGADO; LÓPEZ PALOMEQUE, 2012) ou de destinação de resíduos sólidos, expansão urbana ou exploração 
de madeira (SCHAFER; CHOI, 2006). Fora a proteção do meio ambiente para toda a população, de acordo com estes autores, a intervenção do estado via políticas públicas é necessária na área de turismo devido a vários fatores: a maior parte das atrações turísticas é pública, o turismo tem valor estratégico, e há imperfeições no mercado. Também se deve acrescentar que muitos investimentos em turismo, fundamentalmente em infraestrutura, provêm do estado, o que exige políticas públicas para a alocação e para o gerenciamento de recursos (SHAFER; CHOI, 2006).

Dentro dessa visão mais preocupada com as questões referentes ao meio ambiente, Hall (2000) chama a atenção para a omissão do Poder Público com as questões de interesse coletivo nos últimos anos, privilegiando uma lógica monetarista. As análises econômicas, afirma o autor, não nos informam sobre a utilização produtiva dos recursos, se estes são ou não renováveis ou se determinada atividade tem ou não custos sociais. Hall inclui conceitualmente a elaboração de políticas como parte do planejamento, a partir da definição de Cullingsworth (apud HALL, 2000, p. 8) que diz que o planejamento é um processo propositivo no qual se estabelecem metas e se elaboram políticas e no qual as políticas públicas são aquelas elaboradas pelo governo.

Embora haja certa discrepância entre os autores quanto à posição hierárquica de política e de planejamento, há concordância em que as políticas públicas são ações do estado [governo ou Poder Público]. A política pública está influenciada pela sociedade, pelos valores.

As políticas públicas precisam ser implementadas e para isso há medidas e instrumentos, que vão da decisão de quem tem o poder, o convencimento dos atores sociais, até a aplicação de taxas e/ou multas. A implementação é um processo e negociação que inclui "a intenção do governo com as políticas, e a tensão e a negociação com os atores envolvidos" (KRUTWAYSHO; BRAMWELL, 2010, p. 671). Um estudo desenvolvido por Stevenson, Airey e Miller (2008) enfatiza o papel da negociação permanente na implementação das políticas públicas. De acordo com os autores, a elaboração de políticas públicas é um processo social que envolve uma constante comunicação com as várias esferas em que as decisões são tomadas, não apenas em nível público, mas também dentro de uma sociedade caracterizada pela fragmentação, uma vez que, como 
ISSN: 1983-7151

já foi observado nas análises do fenômeno turístico, este abrange múltiplos setores, partes interessadas assim como não interessadas (SANTANA, 2009).

Os problemas concernentes à elaboração e à implementação de políticas detectados pelos autores ingleses antes mencionados poderiam ser encontrados em outros países, onde ainda não há pesquisas específicas sobre o tema: interesse marginal da administração pública no tema turismo; falta de clareza entre os setores, sobre o que representa o turismo em relação à economia ou à cultura; falta de consenso sobre o que compete a que setor, devido à falta de definição clara das áreas de competência; falta de coerência entre diferentes propostas emanadas dos diferentes setores envolvidos, ora com superposição de políticas, ora com oposição.

O estudo reafirma que o processo de elaboração de políticas de turismo é complexo (assim como é complexo seu planejamento) em função das características do turismo, que perpassa várias esferas de atuação administrativa, que não está restrito a uma área de competência, o que, entre outras coisas, leva a que o turismo não possa ser objeto de políticas exclusivas ou planejamento isolado². Outrossim, a natureza dinâmica do turismo como prática social praticamente impõe a necessidade permanente de replanejamento e, portanto, de revisão de políticas e em todos os níveis, nas quais entram em jogo também questões de poder.

Outro problema que se apresenta é o de aplicar as políticas públicas de turismo. Logar (2010) dividiu os instrumentos para aplicação destas em econômicos, regulatórios e institucionais. Dentro dos primeiros, inclui taxas, impostos e incentivos econômicos; dentro dos segundos, zoneamento e estabelecimento de cotas e entre os institucionais as eco-certificações, as permissões de construção negociáveis e as mudanças no direito à propriedade. Um exemplo de instrumentos econômicos e regulatórios é dado por Nyaupane e Thimoty (2010) para o caso do Butão, onde se optou por um turismo que pudesse dar maior retorno financeiro, estabelecendo-se um mínimo de despesas diárias assim como a obrigatoriedade de contratar um tour organizado e foram delimitadas regiões de circulação dos turistas ocidentais.

2 Há casos paradoxais, como, por exemplo, o de Paris. Uma das cidades que mais atrai turistas por ano, não tinha, no limiar do ano 2000, uma política específica de turismo. O turismo desenvolvia-se com políticas de urbanismo (PEARCE, 1998). 


\section{O PLANEJAMENTO GOVERNAMENTAL E O DISCURSO} SUSTENTÁVEL

A atividade turística é responsável por considerável produção do capital mundial desde o século XX, movimentando bens, serviços, postos de trabalho, gerando renda e crescimento econômico. Por sua amplitude e visibilidade midiática, constrói imagens altamente relevantes para o mercado mundial. Nesse contexto, encontra-se presente nos principais discursos políticos de desenvolvimento socioeconômico e em campanhas partidárias com slogans de desenvolvimento sustentável como solução dos problemas e das crises financeiras de cada lugar que pode ser ou se manter turístico. Em virtude de seu caráter altamente adaptável e inventado, a atividade turística fomenta a circulação de dinheiro, empregos e serviços que englobam setores como cultura, ecologia, lazer e entretenimento, eventos, entre outros.

Para Barretto (2003, p. 21), turismo é "um ato praticado por pessoas que realizam uma atividade específica de lazer, fora das suas respectivas cidades, e se utilizam, para atingir seus objetivos, de equipamentos e serviços cuja prestação constitui um negócio". Enfatiza, ainda, que as relações históricas e a construção social em torno da atividade refletem o modelo capitalista que se prioriza hoje, com fins quase sempre econômicos. Não por acaso, a Organização Mundial do Turismo (OMT, 2001) trata do setor como o conjunto de atividades realizadas durante viagens a lugares distintos de seu contexto habitual, por um período estritamente inferior a um ano, com propósitos de ócio, negócios e/ou outros motivos. Neste sentido, desponta como prática para populações de alta renda como fonte de relaxamento, descanso, comércio e/ou para a obtenção de status social; e também é atraente para o local que o desenvolve, principalmente pela entrada de divisas provenientes dos turistas. Coriolano (2006) ressalta que o setor representa "simultaneamente ócio e trabalho, produto do modo de viver contemporâneo, cujos serviços criam formas confortáveis e prazerosas de viver, restritas a poucos", em que as políticas públicas são indispensáveis para a gestão adequada dos territórios.

O Poder Público tem importante papel no planejamento e na gestão do setor, regulando e orientando as iniciativas públicas e privadas a serem implementadas 
ISSN: 1983-7151

de modo responsável para que propiciem um desenvolvimento harmonioso da economia e da sociedade com o mínimo de prejuízo ao ambiente e à cultura que o concebe.

Para tanto, faz-se necessário refletir sobre a construção discursiva da atividade como fenômeno social e de crescimento econômico que foi adotado pelas políticas públicas no Brasil a partir da década de 1950, baseadas em projetos de industrialização integral para a superação da pobreza. Há, ainda, que se considerar o papel do Estado como órgão planejador e gestor, que orienta os recursos financeiros e promove investimentos diretos no setor, concedendo incentivos fiscais e ordenando os territórios para o desenvolvimento da economia local, regional e nacional.

Quando se pensa em políticas públicas de turismo responsável, alude-se a uma análise que ultrapassa o discurso desenvolvimentista da década de 1950 e o discurso sustentável de 1990; para englobar o planejamento governamental comprometido com um modelo de desenvolvimento harmônico, responsável pelo desenvolvimento social na mesma medida em que prioriza a expansão econômica. Este planejamento tende a minimizar os efeitos negativos do crescimento econômico desordenado, sem comprometimento social eambiental. Desse modo, é capaz de trazer/produzir benefícios para a população do lugar turístico e melhorar o bem-estar das comunidades receptoras, envolvendo os grupos de interesse local nas decisões e nas ações que interferem diretamente no cotidiano de cada território.

O conceito de "turismo responsável" no âmbito das políticas públicas contribui para a conservação e para a diversidade do patrimônio natural e cultural e valorizando a independência administrativa e de gestão pelo fomento do orgulho local. Desse modo, uma política pública de turismo responsável tende a proporcionar experiências mais agradáveis para os turistas por intermédio de comunidades receptoras bem-sucedidas e satisfeitas com o lugar que se constrói para o turismo e que passa a fazer parte de seus modos de vida.

O planejamento governamental notadamente se estrutura na regulação empresarial e estatal para o aumento das riquezas por intermédio do lucro, incorporando ao desenvolvimento uma lógica de sistemas dependentes - em 
escala industrial - que possibilita produzir mais em menos tempo. A este fato sustenta-se um ideal de crescimento econômico com poder descentralizado, no qual todos os cidadãos podem "usufruir" livremente dos benefícios que gera.

Quando Bordini (2007) investigou o processo de descentralização da gestão pública do turismo no estado de Santa Catarina, demonstrou a fragilidade dos processos e dos planos de desenvolvimento que são constantemente comprometidos pela falta de continuidade nas ações, em sua maioria, pela troca de gestão local. Para Solha (2004, p. 145):

A fragilidade das estruturas dos organismos estaduais de turismo pode ser compreendida pelas inúmeras transformações que sofreu ocorridas ao longo do tempo, caracterizada por fusões, extinções, criação de diferentes órgãos e mudança de objetivos, entre outros. Acrescenta-se a isso a descontinuidade das ações geralmente relacionadas às mudanças político-partidárias das gestões estaduais.

O ideário desenvolvimentista brasileiro da década de 1950 contempla uma significação imaginária social que atinge a homogeneização dos usos e dos consumos sociais, de forma que se aproximam da satisfação das necessidades humanas, como se estas fossem, majoritariamente, coletivas, maquiando a imposição dos interesses das grandes corporações do capital industrial, como argumenta Castoríadis (1987). O planejamento governamental tem, nesse sentido, uma função normativa e administrativa que organiza a sociedade conforme o modo de produção vigente.

Ao analisar o planejamento governamental brasileiro instaurado na segunda metade do século XX, Abreu (2001, p. 32) afirma que o planejamento dos governos está baseado numa "racionalização de ações pretensamente distributivas e imbuídas de justiça social para as classes", aludindo à construção do bem-estar social pelo crescimento da economia nacional. Assim, as políticas públicas discursam sobre os interesses sociais, culturais e ambientais que incentivam um crescimento teoricamente sustentável.

O planejamento, em sentido amplo, se revela "mais como técnica burocrática de solucionar ou controlar problemas, inclusive, de ordem social e política, do que um instrumento de desenvolvimento" (RATTNER, 1979, p. 
159), configurando-se como uma forma de manipulação social do sistema de mercado mundial, naturalizando a produção de riquezas e aumentando as desigualdades sociais.

Entre 1950 e 1970, o Brasil teve como prioridade o discurso legitimador de "progresso" com base no crescimento econômico controlado pelo Estado. A economia nacional se abriu para o capital internacional, fato que criou espaços fragmentados de crescimento em virtude das apropriações territoriais seletivas, o que se pode visualizar nos diferentes níveis de expansão econômica e tecnológica das cinco regiões brasileiras (BECKER, 1981). A década de 1980 foi marcada, então, por crises sociais e instabilidades financeiras oriundas da dívida externa, alta inflação e crise de poder dos militares, face às pressões internacionais dos órgãos ligados aos direitos humanos e ambientais, bem como da incapacidade de sustentação da política de crédito concedida aos grandes industriais na década de 1960.

A partir de 1990, a atividade turística foi inserida no território nacional em meio a um liberalismo econômico de integração competitiva. Estabeleceu-se uma economia flexível, cuja competição espacial tendeu à gestão descentralizada dos territórios para superar a contraprodutividade social, em que os estados passam a competir entre si; ao passo que o governo central se reorganizava para participar da economia mundial.

Com a abertura para o mercado internacional, aumentaram-se as relações de exploração e desigualdade social em prol do crescimento econômico como forma de "progresso nacional", o que constantemente modificava a sociedade, os espaços produzidos e o próprio Estado, gerando mais instabilidades e problemas sociais que melhorassem as condições de vida para a população brasileira.

Para Buarque (1993), o "desenvolvimento" é um processo conjunto que contempla o aperfeiçoamento/melhoria do viver social e sua diversidade cultural, política e ambiental, a partir de um conceito de "progresso" que "assuma a essencialidade do progresso econômico submetido a valores e objetos que vão além das metas econômicas" (ibidem, p. 60). Contudo, o Brasil [e praticamente o mundo todo] adotou um "modelo de desenvolvimento" focado na concentração de capital industrial que causou danos irreversíveis ao 
ambiente, como a poluição de seus recursos naturais e o acúmulo de capital nas mãos de uma parcela mínima da sociedade.

Jáem 1990 o"desenvolvimentismo" deulugarao conceito de "desenvolvimento sustentável" como um novo discurso de desenvolvimento com base numa política ecologicamente correta que beneficiasse a sociedade, a cultura e o meio ambiente. O desenvolvimento sustentável, então, seria "aquele que atende às necessidades do presente sem comprometer a possibilidade de as gerações futuras atenderem suas próprias necessidades" (CMMAD, 1991, p. 46).

O discurso da "sustentabilidade" veio socorrer as crises políticas e sociais que enfrentavam a economia brasileira, cujo turismo passa a ter destaque como possível solução dos problemas que historicamente se despontavam. De acordo com Sampaio (et al., 2013, p. 102), os elementos básicos da construção de políticas de turismo sustentável consistem em ser "economicamente eficiente, socialmente inclusivo às comunidades locais e ecologicamente prudente de maneira a preservar a biodiversidade para as gerações futuras". Entretanto, a situação não mudou desde o início do século, quando Rogrigues (2001) já apontava que as transformações espaciais e a nova dinâmica socioeconômica sustentável se concretizam apenas no campo do discurso; e são deficientes na prática, visto que o conceito de sustentabilidade é simplista e contraditório, reduzido a um mito de esperança de dias melhores, situação que não tem mudado nos últimos anos.

\section{AS POLÍTICAS PÚBLICAS DE TURISMO NO BRASIL}

A atividade turística, que toma os discursos de desenvolvimento governamental como política de base para seu desenvolvimento, abrange o discurso sustentável como forma de amenizar as disparidades sociais que são imanentes ao seu próprio modo de produção. Sua implementação e expansão é explicada por modelos de produção com fluxo de capital pelo trabalho humano, uso de tecnologias e elevado índice de produção de mercadorias a serem consumidas, gerando lucro.

Ao Poder Público cabe regular a atividade, orientando o capital privado à apropriação do espaço. Nesse âmbito, o planejamento governamental do 
setor turístico brasileiro baseado no "desenvolvimento sustentável" busca atingir o progresso e a qualidade de vida pelo aumento do consumo, com um discurso que promete combater a fome, a miséria, a criminalidade, as drogas e a prostituição de menores, alavancando a infraestrutura e o comércio dos destinos turísticos para inseri-los na economia global.

As políticas públicas de turismo compreendem as diretrizes e as metas que orientam o desenvolvimento do setor. Para a OMT (2001), a política turística compreende parte do processo de crescimento socioeconômico que garante o bem estar-estar dos cidadãos por intermédio do setor público que é responsável por gerir o turismo, impondo normas e concedendo incentivos à iniciativa privada para que os investimentos não ocorram de modo desordenado e ineficiente.

A trajetória das políticas públicas brasileiras para a atividade turística foi marcada por relações desconexas dos planos instaurados no país, num movimento quase inexistente até 1990. O planejamento governamental brasileiro instaurou diversos planos econômicos, como Plano Salte (1949-53), Plano de Metas (195660), Plano Trienal de Desenvolvimento Econômico-Social (1963-65), Plano Decenal de Desenvolvimento Econômico e Social (1967-76) e os Planos Nacionais de Desenvolvimento I (1972-74), II (1975-79) e III (1980-84). Contudo, a atividade turística foi sempre negligenciada, marginalizada ao crescimento e à obtenção de lucro, secundária a qualquer outra forma de ganho.

Uma síntese das políticas públicas de turismo no Brasil pode ser encontrada em Bregolin (2005, p. 89), que elabora um quadro bastante completo e ilustrativo sobre a história das mesmas e das ações que antecedem. Não constituem exatamente políticas públicas, mas são ações do governo, antecedentes, tais como o Decreto 3.216 de 23/03/1932 que fixa a temporada de turismo no Distrito Federal (Rio de Janeiro na época), a Lei n²5 de 30/11/1937 de proteção aos monumentos de interesse histórico e artístico nacional, e o Decreto 2.240 de 23/07/1940 que regulamentou as atividades das agências de turismo (BREGOLIN, 2005, p. 88; CAVALCANTI; HORA, 2002, p. 55).

Bregolin (2005, p. 92) também nota que há políticas que indiretamente incidem ou são tangenciais a uma política de turismo, por exemplo, a Política Nacional de Meio Ambiente (Lei 6.938 complementada pela Lei 7.347) que teve 
repercussão nas políticas de turismo, com o lançamento do produto "turismo ecológico" pela EMBRATUR.

Os primeiros decretos e iniciativas referentes ao turismo estavam concentrados na comercialização de passagens domésticas e internacionais. Logo, a Divisão de Turismo, primeiro órgão oficial brasileiro, iniciou suas atividades em 1939, fiscalizando as ações das agências de viagem. Posteriormente, a atividade passa a integrar diferentes setores da administração pública nacional: Departamento Nacional de Informações, do Ministério da Justiça e Negócios Interiores (1946); Departamento Nacional de Imigração, posterior Instituto de Imigração e Colonização, do Ministério do Trabalho, Indústria e Comércio (1946-58); e a Combatur - Comissão Brasileira de Turismo - (1958-62), órgão subordinado diretamente à Presidência da República; à Divisão de Turismo e Certames, do Departamento Nacional do Comércio, do Ministério da Indústria e do Comércio (1961-66); Ministério da Indústria e Comércio (1966-90); Secretaria de Desenvolvimento Regional da Presidência da República (1990-92); Ministério da Indústria, do Comércio e do Turismo (1994-98); e Ministério dos Esportes e do Turismo (1999-2002).

Em 1996 define-se a Política Nacional de Turismo, cria-se o Conselho Nacional de Turismo (CNTur) e a Empresa Brasileira de Turismo (EMBRATUR), grande marco para a atividade turística no país, que passou a ser valorizada, principalmente, pela ascendente participação do turismo no PIB mundial; a necessidade de diversificação das atividades produtivas nacionais e a difusão às potencialidades naturais brasileiras, considerando-se o binômio sol-praia e ecossistemas como Pantanal e Amazônia (CRUZ, 2002).

A política de 1996 objetivava ordenar o setor público, definindo parâmetros de planejamento e execução para governos e municípios, orientar o setor privado e (re)configurar os territórios turísticos nacionais para inseri-los no mercado internacional, no qual se promoveram ações interministeriais e intersetoriais para remover os entraves burocráticos ao ingresso de turistas estrangeiros, a exemplo dos acordos bilaterais com a França e os EUA, flexibilizando a concessão de vistos a turistas. Conciliaram-se, também, diversos programas de desenvolvimento para a expansão do setor, como Programa de Infraestrutura 
ISSN: 1983-7151

Básica e Turística, Programa de Geração de Oportunidades de Negócios, Programas de Desenvolvimento, os Programas de Desenvolvimento do Turismo - PRODETUR Nordeste, Amazônia Legal/Centro-Oeste e Sul-MS, os Programas Hidrovia Tietê-Paraná e Desenvolvimento Turístico do Vale do Ribeira, em Iguape/ SP e obras direcionadas à duplicação e à melhoria de estradas, executadas no Programa Brasil em Ação (1996), principalmente na Região Sul e nas ligações desta região aos parceiros do Mercosul (ibidem, 2002).

A primeira Política Nacional de Turismo (1996) se sustentou, assim, na implantação de infraestrutura básica e turística, capacitação de recursos humanos, modernização da legislação, descentralização de gestão pública e promoção do turismo no Brasil e no exterior. Em âmbito administrativo, transferiram-se as unidades públicas de turismo para Brasília e reformulouse a EMBRATUR. Criou-se, ainda, o Programa de Financiamento de Agências de Turismo, bem como a ampliação do prazo de reembolso das operações aprovadas com recursos do Fundo Geral de Turismo - FUNGETUR ${ }^{3}$ - de dez para treze anos, e o prazo de carência de três para quatro anos, atendendo a um antigo pleito do setor hoteleiro para estimular novos investimentos. É nesse período de organização política que o turismo se consolida e o apoio do Governo Federal com estratégias de marketing internacional e valorização das viagens domésticas aumenta consideravelmente o fluxo de turistas no país.

O Ministério do Esporte e do Turismo regulamentada, em 15 de março de 2001, o Programa Nacional de Infraestrutura Turística - PROINTUR, gerido pela EMBRATUR e fundamentado no discurso do "desenvolvimento sustentável", a fim de propiciar condições para o desenvolvimento socioeconômico, financiando a implantação de infraestrutura e serviços de finalidade ou interesse turístico, mantido com recursos do Orçamento Geral da União.

Ao estudar a política de turismo no Brasil e a atuação da EMBRATUR até a década de 1990, Cavalcanti e Hora (2002) salientam que as estruturas políticas

3 O FUNGETUR é um mecanismo de crédito essencial ao fomento do turismo e estratégia para desenvolvimento socioeconômico, geração de emprego e renda, inclusão social e melhoria da qualidade de vida, instituído pelo Decreto-Lei $\mathrm{n}^{\circ} 1.191$, de 27 de outubro de 1971. Tem por finalidade prover recursos para o financiamento de empreendimentos, obras e serviços considerados de interesse para o desenvolvimento do turismo nacional, em cumprimento ao disposto no parágrafo único do art. 19 do Decreto-Lei n 55, de 18 de novembro de 1966, referente à criação de fundo especial. 
brasileiras exigem ações voltadas à promoção, à coordenação e ao controle do desenvolvimento turístico, bem como novas formas de planejamento e de gestão alicerçadas a uma política institucional que seja capaz de resgatar a cidadania e promover a solidariedade entre iguais e, especialmente, entre grupos e realidades diferentes.

O ideário de "desenvolvimento sustentável" baseado nos atrativos naturais passa a ter grande força política. Em 31 de julho de 2002, é criado o Comitê Gestor do Programa Polos de Ecoturismo no Brasil. Suas atribuições eram de orientar e definir políticas para os polos já existentes e propiciar a formação de novos polos, ampliando a oferta nacional e definindo novas formas de gestão, com o apoio dos serviços públicos federal, estadual e municipal, para a ampliação da infraestrutura básica e turística. Priorizam-se regiões específicas, como Amazônia, Pantanal, Bonito e áreas litorâneas na região do Nordeste brasileiro e em Unidades de Conservação, em especial, no Rio de Janeiro.

Em 2003, o governo Lula (2003-10) institui o Ministério do Turismo (Mtur) exclusivamente para planejar e gerir o setor no país. Neste mesmo ano, o MTur lança o Plano Nacional de Turismo (PNT, 2003-06), que passa a orientar estados, municípios e Governo Federal quanto às atividades a serem implementadas, o direcionamento dos recursos e financiamentos, bem como as diretrizes e as metas a serem alcançadas para o crescimento do setor e para a ampliação do mercado internacional.

Aindacomfoconochamado"turismosustentável", odiscursodasustentabilidade passa a permear nos territórios e no imaginário das comunidades receptoras como uma alavanca social, regulando a apropriação privada dos espaços de uso do turismo, cuja presença das políticas públicas teoricamente vem assegurar que os objetivos de progresso e desenvolvimento socioeconômico sejam atingidos, em consonância com as relações ambientais locais.

\section{O "NOVO" TURISMO BRASILEIRO}

O "novo" discurso pregado pelo MTur é desenvolver o setor turístico como atividade econômica sustentável de modo que promova a "inclusão social" 
por intermédio de um modelo de gestão descentralizada. Azevedo (2002, p. 191) salienta que a descentralização incide sobre organismos públicos especializados que caracterizam a funcionalidade; ou sobre distritos municipais, comunas, províncias, estados, departamentos e regiões, correspondendo à descentralização administrativa; ou sobre a colaboração da iniciativa privada, a quem o Estado transfere parte de suas atribuições específicas, mediante atos de autorização, concessão ou permissão.

Mantendo o desenvolvimento atrelado ao crescimento econômico reproduzido desde os anos de 1950 e à sustentabilidade de 1990, a "inclusão social" aparece pela inserção da população brasileira no mercado turístico via geração de empregos, barateamento do turismo interno e facilidade de financiamento das viagens a determinados grupos, como os aposentados. Desse modo, o PNT (2003) é definido como um instrumento de planejamento, com objetivo de desenvolver o país de acordo com suas diversidades regionais, naturais e culturais de cada região. Contudo, como pensar e colocar em prática um modelo único de desenvolvimento que equilibre todas as variáveis sociais, ambientais, econômicas e culturais de um país com tamanhas proporções e diversidades socioeconômicas, culturais e ambientais?

Inegavelmente o turismo contribui, como produtor de riquezas, para o progresso nacional brasileiro. Entretanto, "não se pode esperar que o turismo, como setor da vida social, traga a solução de todos os problemas de emprego do país ou a tão sonhada justiça social" (CRUZ; SANSOLO, 2005, p. 05), como aludem os planos governamentais, visto que constitui uma atividade que segue a produção industrial capitalista e, naturalmente, também produz marginalidades socioespaciais, culturais e degradação ambiental, opondo-se ao seu discurso sustentável.

A apresentação de um órgão unicamente responsável pela atividade é questionada pelos autores ao apontarem que a criação de um Ministério isolado não é indicador de desenvolvimento político. Como exemplo citam a bemsucedida administração pública alemã, que tem uma Divisão Política de Turismo subordinada ao Ministério da Economia e do Trabalho. A criação do MTur se faz paradoxal, já que ao mesmo tempo em que é ministério, o turismo é "um tema inexistente ou periférico nos ministérios que têm ingerência direta sobre seu 
desempenho, a administração pública federal vê como única alternativa para tentar reverter este quadro criar um Ministério só para ele" (ibidem, p. 03).

A crítica decorrente da centralização dos assuntos do turismo parte do fato de que ele está sempre à margem de outros ministérios nas questões referentes ao desenvolvimento nacional, mesmo trazendo uma política de correlação ministerial, na qual lhe é dada a função de "estabelecer as diversas interfaces com os distintos Ministérios e órgãos governamentais dos quais o turismo depende, direta e indiretamente" (PNT, 2003, p. 33). Cabe ressaltar que a criação do MTur, ao passo que beneficia o setor, não pode ser considerado a solução dos entraves econômicos, sociais e culturais do país; tampouco pode desvincular-se das outras políticas públicas ministeriais de desenvolvimento do Brasil.

Lanzarini (2006, p. 32) relata que "não se pode pensar no turismo como a 'salvação' do mundo. (...) não está em sua lógica resolver os problemas de distribuição de renda e desemprego, nem tão pouco, acabar com as tensões sociais da sociedade moderna". É ingênuo, portanto, idealizar a atividade como promotora do desenvolvimento social, nem tampouco caracterizá-la como predatória ou destruidora dos espaços que consome. É, antes de tudo, ambígua, pois ao mesmo tempo em que promove riquezas, empregos e melhoria de vida para a população do destino turístico, também produz pobreza, exclusão social e fragmentação do espaço.

Essas políticas públicas têm se baseado no discurso da sustentabilidade para atuar nos espaços habitados e no imaginário das comunidades receptoras como uma alavanca para o desenvolvimento local e para regular a apropriação privada dos espaços de uso do turismo. Os bons resultados de suas ações dependem do envolvimento e do comprometimento de estados, municípios e da iniciativa privada na construção de um turismo comprometido com o bem-estar econômico, sociocultural e ambiental. Antes de "sustentáveis", essas políticas precisam ser "responsáveis" pelos processos evolutivos da sociedade e do meio ambiente, ultrapassando as barreiras do discurso político para ações concretas que beneficiam todas as instâncias do progresso da humanidade.

Não se constrói uma "cultura turística" apenas pela atuação de um órgão governamental, e sim ao longo de um processo de aceitação sociocultural, que implica um planejamento construtivo, baseado nas experiências históricas e 
ISSN: 1983-7151

nos processos sociopolíticos de cada região do país em prol de um progresso que articule a responsabilidade socioambiental, socioeconômica e sociopolítica, numa gestão responsável do turismo.

Reflexões acerca da redução dessas desigualdades salientadas pela política pública precisam ser evidenciadas, visto o caráter mitificador do discurso. De quais desigualdades se fala? Seria possível pensar e se apoiar na atividade turística como fonte de riqueza para a redução de desigualdades econômicas e sociais nas diferentes regiões do país de maneira uniforme e pré-moldada em programas de intervenção governamental e treinamento de recursos humanos? A resposta não parece tão simples.

Ao identificar o setor turístico como um importante vetor de desenvolvimento, o PNT (2003-06) aponta a atividade como prioritária para o progresso nacional, propiciando desenvolvimento econômico e redução das desigualdades sociais. "O turismo tem de interferir nas desigualdades regionais, amenizando-as, visto que, destinos turísticos importantes no Brasil estão localizados em regiões mais pobres" (PNT, 2003, p. 04).

A ideia de "sustentabilidade" é evidenciada pela erradicação da miséria, da qual o setor, discursivamente, tem uma parcela de responsabilidade. Nessa perspectiva, a Secretaria Nacional de Programas de Desenvolvimento do Turismo lança em 2005 o projeto "Turismo Sustentável e Alívio da Pobreza no Brasil", tratando do setor como aquele que atende às necessidades dos turistas e das regiões receptoras, gerenciando as necessidades econômicas, sociais e estéticas sem desprezar a manutenção da integridade cultural local.

Outro programa lançado para atender demandas antes marginalizadas pela atividade turística como uma forma de "turismo popular" lançado em 2006 foi o "Vai Brasil", elaborado para aumentar a oferta e a procura dos destinos brasileiros em períodos de baixa temporada, diminuindo os efeitos da sazonalidade e dando a oportunidade dos integrantes da cadeia produtiva do turismo divulgarem seus produtos em rede nacional, via Internet. O barateamento dos pacotes turísticos prevê a comercialização não comissionada dos produtos, em formas de pagamento facilitadas para a população de baixa renda brasileira. 
Em 2007 uma nova versão da Política Nacional de Turismo estabelece projetos e ações previamente definidos pela gestão política anterior, de mesmo governo. Conforme estatísticas apresentadas no relatório oficial que subsidia o PNT (2007-10) houve, como impacto da política anterior, a criação de inúmeros empregos diretos, aumento do consumo interno de viagens em baixa temporada, aumento da entrada de divisas estrangeiras e investimentos públicos, diversificação da oferta turística, entre outros fatores que basicamente se referem ao crescimento econômico e ao ideário de progresso de 1950.

O PNT (2007-10), como política de integração regional, vem com a proposta de criar novos espaços e arranjos produtivos locais para atrair mais público e produzir um território turístico mais abrangente, aumentando a diversidade de oferta de lugares onde a atividade turística é incipiente. O setor passa a compor o cenário do desenvolvimento nacional, abrindo-se para o mercado global, expandindo as fronteiras socioculturais e econômicas com a internacionalização dos territórios.

Fernandes (1998) aponta que as relações entre nações deixaram os domínios exclusivos dos Estados, de caráter político-econômico, para compor uma ordem internacional que agrega uma interdependência social. No caso específico do turismo, a divulgação do lugar e dos serviços, com consequente aumento das visitas internacionais, estreita as relações entre países, aproximando economias que passam a cambiar moeda, trocar relações sociais e experiências culturais, aproximando-os, tal qual Barretto et al. (2003) descreve a respeito da colonização argentina no Balneário de Canasvieiras, norte da Ilha de Santa Catarina, Brasil.

Para Coriolano (2006), o turismo traz consigo, como negócio, o lucro e a distribuição injusta de riqueza, sendo uma contradição propor desenvolvimento local, social e cultural, pois transforma o espaço em mercadoria, massificando culturas e priorizando os que vêm de fora em detrimento dos residentes do lugar turístico. Entretanto, também oportuniza ganhos para trabalhadores e divisas para regiões mais pobres. Desse modo, o turismo pode ser visto positivamente "na contradição de que destrói e beneficia, (...) na perspectiva da tese, que ao incorporar a antítese, o seu 'contraponto', transforma-se em síntese, ponto e novamente contraposição da posição" (ibidem, p. 371), tal qual se deu o processo evolutivo da sociedade moderna. 
A partir de 2011 a política nacional passa a priorizar os investimentos em criação e/ou melhoria da infraestrutura de acesso e esportiva para que o país possa sediar os dois maiores eventos esportivos do mundo: a Copa do Mundo de 2014 e as Olimpíadas de 2016. Nesse contexto, alguns planos de ações são trabalhados pelo MTur para o aperfeiçoamento de recursos humanos; infraestrutura urbana, via Plano de Aceleração do Crescimento (PAC); e de marketing nacional, via Plano Cores do Brasil; e internacional, via Plano Aquarela. Entretanto, a gestão instaurada em 2011 apenas lançou um novo Plano Nacional em meados de 2013 com o discurso do "turismo fazendo muito mais pelo Brasil", cujo ideário de desenvolvimentismo continua a demarcar uma atividade que amplia suas fronteiras pelo aumento do consumo e expansão de infraestrutura, discursivamente ligado à melhoria da qualidade de vida dos praticantes do turismo e dos habitantes nos destinos turísticos.

Esses destinos passam a compor planos de marketing sustentável que elevam, hipoteticamente, a qualidade social dos lugares por meio de certificações verdes, legitimando um "consumo consciente" que alivia as tensões sobre os danos causados ao longo da história nos lugares turísticos. Para Bowman (2011), a implantação de certificações de Turismo Sustentável, no caso de países pobres, é resultado do diálogo e da decisão política sobre o tipo de desenvolvimento turístico adotado, com maior conscientização na comunidade empresarial das necessidades futuras. Contudo, no caso do Brasil, Oliveira e Rossetto (2013, p. 338) ressaltam que:

Os planos e os programas governamentais nacionais tiveram como uma de suas finalidades o estímulo ao turismo sustentável, porém foram desenvolvidos sem integração com outras iniciativas, sofrendo com a descontinuidade e com a consequente falta de credibilidade junto aos integrantes do setor. Assim, não conseguem ter uma perenidade e obter consistência ao longo do tempo e credibilidade perante aos diversos interessados na cadeia produtiva do turismo até chegar aos turistas.

Sansolo (2013) analisou as políticas e os planos federais de turismo na região amazônica, onde constatou avanços na participação local no processo de construção de políticas e planos, mesmo sendo a política amazônica, ainda, centralizadora. Contudo, refere-se ao modelo de desenvolvimento político 
nacional como "um processo de seleção e exclusão de territórios, baseados na lógica da localização industrial e no entendimento do território como oportunidade de acumulação, de mercantilização de seus atributos" (ibidem, p. 115), a fim de reproduzir o capital. Nesse sentido, o direcionamento econômico nas políticas de desenvolvimento do turismo privilegia o setor privado e o consumo da demanda [que é externa] em detrimento das particularidades locais, encaradas apenas como externalidades.

Os dilemas e os impasses político-administrativos parecem se perpetuar: o discurso quantitativo de progresso, o crescimento econômico prioritário, a lógica do capital industrial e o mito do "desenvolvimento sustentável" que supre as necessidades de todos e promove igualdade social precisa, realmente, de mais comprometimento e responsabilidade por parte dos governos, dos investidores privados e da sociedade civil. O discurso político, que a cada governo escolhe um slogan diferente, segrega as dimensões do desenvolvimento, da equidade social e reduz as sociedades às estatísticas a partir de um conceito puramente matemático de crescimento e progresso.

A perspectiva de um governo que privilegia um "turismo sustentável" como forma de mudar o mundo é minimamente utópica e ingênua. Para um "turismo sustentável" seria preciso uma sociedade diferente e, principalmente, um modo de produção de riquezas que privilegiasse - além da economia - a sociedade, a cultura e o ambiente, numa perspectiva mais humana que estatística.

\section{CONSIDERAÇÕES PARA UMA POLÍTICA PÚBLICA DE TURISMO} RESPONSÁVEL

A atividade turística não obteve êxito em suas ações políticas até 2002. As ações públicas e privadas eram desconexas e, consequentemente, conflituosas, visto que seu planejamento era praticamente inexistente, mesmo quando, no Governo $\mathrm{FHC}^{4}$, institui-se uma Política Nacional de Turismo, que regulava o planejamento, mas que, em oito anos, não foi implementada em sua totalidade, e sim com poucas iniciativas que acabaram abortadas por apresentar resultados insatisfatórios.

4 Período de Governo do Presidente Fernando Henrique Cardoso com dois mandados, entre 1995 e 2002. 
O Governo Lula ${ }^{5}$, que se instaura em 2003, adota um discurso de inclusão social pela geração de empregos e o próprio consumo turístico. Contudo, as prioridades numéricas dos planos políticos pouco se relacionam com o vasto e diversificado contexto social que o país apresenta. Trata-se de um discurso que reitera os mesmos chavões sobre o turismo como gerador de divisas que povoaram toda a literatura da década de 1970, e que foi desconstruído pelo próprio banco mundial em 1979 na reunião coordenada pelo sociólogo Emanuel de Kadt, assessor deste órgão internacional (DE KADT, 1979). Essa roupagem do discurso político, que deixou de priorizar somente o crescimento econômico para aludir ao contexto social e ambiental, em pouco modificou a prática que leva o setor a seu desenvolvimento, contrapondo o "novo" discurso. A sustentabilidade tão almejada como salvação dos males humanos tendo como base fundamental a atividade turística não é, e nunca foi, capaz de se efetivar, dado os interesses econômicos e expansionistas que imperam e desequilibram as relações entre turistas e habitantes locais, empresários e governo, humanidade e natureza.

O Governo Dilma6 instituído a partir de 2011, embora não tenha implementado oficialmente uma política pública até o início de 2013, manteve as ações pleiteadas no Governo Lula, dando prioridade, especialmente, à captação de recursos e ampliação de infraestrutura para que o país sedie dois grandes eventos mundiais: a Copa do Mundo de Futebol em 2014 e as Olimpíadas em 2016. Atrelado ao antigo plano de desenvolvimento, instituíram-se ações de promoção do país em nível internacional e a implementação de cursos de qualificação e suporte de recursos humanas nas cidades-sede dos respectivos eventos. Contudo, a medição desses "avanços" está alicerçada em relações efetivamente quantitativas, que pouco demonstram a qualidade e a continuidade dos processos locais de expansão e melhoria da atividade turística.

Pensar numa forma de "turismo responsável", baseado no Código Mundial de Ética do Turismo (1999) e fundamentado na tolerância e respeito à diversidade humana, parece mais eficiente e menos utópico. Seu planejamento está bastante

5 Período de Governo do Presidente Luiz Inácio Lula da Silva com dois mandados, entre 2003 e 2010.

$6 \quad$ Período de Governo da Presidente Dilma Rousseff, entre 2011 e 2014. 
próximo da ideia de "sustentável", focado a partir do destino turístico e visando a um lugar melhor para as pessoas viverem e, consequentemente, visitarem. Essa perspectiva consiste num processo de melhorias de dentro para fora, cuja atividade é responsabilidade de todos os envolvidos, seja o Poder Público, a comunidade local, os empresários e os próprios turistas, conforme a Declaração da Cidade do Cabo sobre os destinos de "turismo responsável" publicada em 2002.

Além do cuidado com a comunidade receptora de turistas, o planejamento responsável do turismo deve propiciar ao visitante uma experiência que corresponda às expectativas criadas pelas ações promotoras das localidades, com padrões de preço e atendimento condizentes com a ética comercial, fatores que só podem ser norteados por uma política pública e um planejamento governamental responsável com o setor turístico e com a humanidade. Mas o que vem acontecendo no Brasil a partir das ações de expansão do turismo desde 20117? Um exemplo bem marcante do último ano é a corrida mercantilista de superinflação que a mídia tem apontado nas cidades-sede da Copa 2014, com preços abusivos dos serviços turísticos de hospedagem, alimentação, passagens aéreas, entretenimento e agenciamento. Concomitantemente, tem havido uma oposição maciça à Copa nas ruas, com slogans solicitando "saúde e educação padrão Fifa ${ }^{8 "}$ para suprir as carências sobre as necessidades básicas da população brasileira. Com foco no setor turístico, um evento deste porte, que traz benefícios de marketing internacional em massa e divisas concentradas, não pode simplesmente reproduzir o desenvolvimentismo da década de 1950, com as consequências por todos conhecidas. Estas ações não parecem estar de acordo com uma política pública de sustentabilidade com respeito ao meio ambiente social, cultural, econômico e político; e, sobretudo, com a política social que estes três últimos governos têm privilegiado.

O turismo só pode vir a ser realmente eficiente para o território nacional a partir de uma construção histórica, lenta e planejada de ações públicas responsáveis e orientadas por políticas consistentes. Não é apenas constituindo um Ministério que o turismo no Brasil terá um planejamento de acordo com os novos paradigmas mundiais, mas sim adotando uma nova visão, deixando de lado o velho discurso economicista do crescimento e elaborando políticas

7 Note-se que não são consideradas políticas nem sequer planejamento; somente ações.

8 Fédération Internationale de Football Association. 
capazes de abranger todas as instâncias do desenvolvimento e de dar conta das especificidades locais. É preciso, assim, repensar as políticas, as ações, os discursos e, acima de tudo, ter em conta a sociedade mais ampla.

Uma nova política é possível e necessária. Novos contextos e novos cenários se constroem ao longo do tempo e a atividade turística ganha, no Brasil, a cada ano, mais visibilidade, importância e investimento técnico-científico. A gestão da atividade depende não apenas de um processo de mudança teóricometodológica e técnica, mas também de uma mudança social que produza novos territórios e outras relações de trabalho e consumo advindos de uma realidade social e política que possa transcender a uma política pública responsável de base local, em âmbito nacional e global.

O planejamento governamental se faz necessário para regular as ações da iniciativa privada e organizar os investimentos do setor público voltados ao turismo. O espaço usado para seu crescimento não pode ser dissociado do contexto econômico que o engloba e precisa inserir-se na sociedade de forma regulada e condizente com os aspectos socioculturais locais. Assim, o Poder Público, em todos os níveis, tem a função de orientar esse crescimento, porém, não pode ser o único responsável pelas incoerências e falhas dos processos nacionais de crescimento e expansão.

O setor turístico, contudo, não necessita apenas de planejamento governamental e de políticas públicas. A criação de um ministério tem um papel organizador do arcabouço de ações despendidas para a atividade, com a proposta de racionalizar os gastos de modo mais hegemônico no território nacional para a solidificação de uma estrutura turística integrada nas diversas regiões do país que já desenvolvem a atividade e direcionando, assim, os investimentos no setor para a maximização do quadro turístico nacional. Entretanto, como sempre ocorre no planejamento de governos, o capital está à frente, criando demandas e cobrando ações do Poder Público no sentido de maximizar as condições de lucro em detrimento do desenvolvimento responsável, que abrange riqueza, cultura, ambiente e bem-estar social.

O Brasil encontra-se em um processo global de desigualdades do qual nenhum governo pode solucionar de imediato. O que pode ser feito, da parte 
do Poder Público, é uma reestruturação em suas ações, a fim de formular uma efetiva "Política Pública de Turismo Responsável", que contemple diretrizes e metas capazes de direcionar os trabalhos continuadamente, de forma concreta e em benefício de todos.

\section{REFERÊNCIAS}

ABREU, S. de. Planejamento Governamental: A Sudeco no espaço mato-grossense. Contexto, propósitos e contradições. Tese de doutorado. Universidade de São Paulo: Faculdade de Filosofia, Letras e Ciências Humanas, 2001.

AZEVEDO, J. Turismo: políticas públicas, recursos humanos e educação ambiental. In: IRVING, M. A. \& AZEVEDO, J. Turismo: o desafio da sustentabilidade. São Paulo: Futura, 2002.

BARRETTO, M. O imprescindível aporte das ciências sociais para o planejamento e a compreensão do turismo. Horizontes Antropológicos, Porto Alegre, ano 9, n. 20, 2003, p. 15-29.

et al. Turismo, políticas públicas e relações internacionais. Campinas/SP: Papirus, 2003 - (Coleção Turismo).

Planejamento responsável do turismo. Campinas/SP: Papirus, 2005. - (Coleção Turismo).

BECKER, B. K. Modernidade e Gestão do território no Brasil: da integração nacional à integração competitiva. In: Espaço \$ Debates - Revista de Estudos Regionais e Urbanos. São Paulo: Núcleo de Estudos Regionais e Urbanos, 1981.

BENI, M. C. Análise Estrutural do Turismo. 7. ed. São Paulo: SENAC São Paulo, 2002.

BORDINI, C. V. O processo de descentralização da gestão pública de turismo no estado de Santa Catarina. Escola de Comunicação e Artes da Universidade de São Paulo. São Paulo/SP: USP, 2007. - (Tese de Doutorado).

BOWMAN, K. S. Sustainable tourism certification and state capacity: keep it local, simple, and fuzzy. International Journal of Culture, Tourism and Hospitality Research, v. 5, n. 3, 2011, pp. 269-281.

BRASIL, Decreto-lei 1.191, de 27 de outubro de 1971. Dispõe sobre os incentivos fiscais ao turismo, e dá outras providências.

BRASIL, Decreto-lei 55, de 18 de novembro de 1966. Define a política nacional de turismo, cria o Conselho Nacional de Turismo e a Empresa Brasileira de Turismo, e dá outras providências. 
BRASIL, Ministério do Turismo. Plano Nacional de Turismo: Diretrizes, Metas e Programas (2003/07) - PNT. Ministério do Turismo: Brasília, 2003.

BRASIL, Ministério do Turismo. Plano Nacional de Turismo: uma viagem de inclusão (2007/10) - PNT. Ministério do turismo: Brasília, 2007.

BREGOLIN, Michel. Desenvolvimento turístico. Análise das condições legais existentes para a gestão do turismo sustentável pelas administrações municipais. $\mathbf{O}$ caso de Bento Gonçalves. Dissertação. Mestrado em Turismo. Universidade de Caxias do Sul: UCS, 2005.

BUARQUE, C. A desordem do progresso: o fim da era dos economistas e a construção do futuro. 4. ed. Rio de Janeiro: Paz e Terra, 1993.

CAPECE, G. Política Turística. Metodología para su concepción y diseño. Buenos Aires: Ladevi. Col. Política Turística, 2000.

CASTORIADIS, C.. As encruzilhadas do labirinto 2: os domínios do homem. Rio de Janeiro: Paz e Terra, 1987.

CAVALCANTI, Keila B.; HORA, Alberto S. S. da. Política de Turismo no Brasil. Revista Turismo em Análise, v. 13, n. 2, nov. 2002, pp. 54-73.

Código MUNDIAL DE ÉTICA DO TURISMO, 1999. Disponível em: http://www. madeiraislands.travel/pls/madeira/docs/F1522518145/Codigo\%20Etica\%20do\%20 Turismo-PT.pdf . Acesso em 02/09/11.

COMISSÃO MUNDIAL SOBRE MEIO AMBIENTE E DESENVOLVIMENTO. Nosso futuro comum. 2. ed. Rio de Janeiro: Editora da Fundação Getulio Vargas, 1991.

COOPER, Cris (et al). Turismo, princípios e práticas. 2. ed. Porto Alegre: Bookman, 2002.

CORIOLANO, L. N.. Turismo: prática social de apropriação e de dominação de territórios. Em publicación: América Latina: cidade, campo e turismo. Amalia Inés Geraiges de Lemos, Mónica Arroyo, María Laura Silveira. CLACSO, Consejo Latinoamericano de Ciencias Sociales, San Pablo. Diciembre 2006.

CRUZ, R. C. A. \& SANSOLO, D. G.. Plano Nacional de Turismo: uma análise crítica. Caderno Virtual de Turismo, 2005. ISSN: 16776976. Disponível em: http://www.ivt-rj.net/caderno/ anteriores/10/davis/davis1.htm. Acesso em 20 out. 2005.

CRUZ, R. C. A. Política de Turismo e Território. 3. ed. São Paulo: Contexto, 2002. - (Coleção Turismo). 
DECLARAÇÃO DA CIDADE DO CABO: DESTINOS DE TURISMO RESPONSÁVEL. Cidade do Cabo, agosto de 2002. Disponível em: http://www.aethnic.org/mm/The\% 20Cape\%20 Town\%20Declaration.pdf . Acesso em 02 set. 2011.

DE KADT, E. Tourism, passport to development? Oxford: Oxford University Press, 1979.

FÁVERO, Ivane M. R. Políticas de Turismo. Planejamento na Região Uva e Vinho. Caxias do Sul: EDUCS, 2006. - [Série Turismo].

FERNANDES, A. J. Relações internacionais contemporâneas: do mundo da Europa à Europa do mundo. Itajaí/SC: Univali, 1998.

GOELDNER, Charles; BRENT RITCHIE, J.R.; McINTOSH, Robert. Turismo, princípios, Práticas, Filosofias. Porto Alegre: Bookman, 2002.

HALL, C. Michael. Tourism Planning. Policies, Processes and Relationships. England: Pearson Education Ltd., 2000 - [Themes in tourism collection].

KERR, B.; BARON, G.; WOOD, R. T. Politics, Policy and Regional Tourism Administration: a case examination of Scottish area tourism board funding. Tourism management, v. 22, 2001, p.649-657.

KRUTWAYSHO, O.; BRAMWELL, B. Tourism Policy Implementation and Society. Annals of Tourism Research, v. 37, 2010, p. 670-691.

LAKATOS, E. M.; MARCONI, M. A.. Metodologia do trabalho científico: procedimentos básicos, pesquisa bibliográfica, projeto e relatório, publicações e trabalho científico. 7. ed. São Paulo: Atlas, 2009.

LANZARINI, R. Políticas públicas de turismo e o contexto de Mato Grosso do Sul entre 2003-06: seus interesses correlatos. Programa de Pós-Graduação em Geografia. Aquidauana//MS: UFMS, 2006. - (Dissertação de Mestrado).

LICKORISH, Leonard \& JENKINS, Carson. An introduction to tourism. Oxford: Butterworth Heinemann, 1996.

LOGAR, Ivana. Sustainable tourism management in Crickvenica, Croatia: An assessment of policy instruments. Tourism Management, v. 31, 2010, p. 125-135.

NYAUPANE, G.; THIMOTY, D. Power, Regionalism and Tourism Policy in Bhutan. Annals of Tourism Research, v. 37, n. 4, 2010, p. 969-988.

OliVEIRA, M. A. S.; ROSSETTO, A. M.. Políticas Públicas para o Turismo Sustentável no Brasil: evolução e perspectivas de crescimento para o setor. Revista Turismo Visão e Ação, v. 15, 
ISSN: 1983-7151

n. 3, set-dez 2013, pp. 322-339. Disponível em: <http://dx.doi.org/10.14210/rtva. v15i3>. Acesso em: 04 abr. 2014.

OMT. Introdução ao Turismo. São Paulo: Rocca, 2001. - Tradução de Dolores Martin Rodrigues Córner;

PEARCE, Donald. Tourism Development in Paris. Public Intervention. Annals of Tourism Research, v. 5, n. 2, 1998, p. 457-476.

RATTNER, H.. Planejamento e bem estar social. São Paulo: Perspectiva, 1979.

RICHARDS, L. Political implications of Chinese tourism policy. Annals of Tourism Research: A social sciences journal, v. 10, n.3, 1983, pp. 395-413.

RODRIGUES, A. M.. O mito da sustentabilidade da atividade turística. In: BANDUCCI JR, A.; MORETTI, E. C. \& RODRIGUES, A. M.. Qual Paraíso?: turismo e ambiente em Bonito e no Pantanal. São Paulo/SP: Chronos, 2001. - (Coleção Tours).

SAMPAIO, C. A. et al. Políticas Públicas do Turismo e Sustentabilidade: a interrelação na Esfera Nacional, Estadual e Local. Revista Turismo Visão e Ação, v. 15, n. 1, jan-abr 2013, pp. 95-111. Disponível em: <http://dx.doi.org/10.14210/rtva.v15i1>. Acesso em 04 abr. 2014.

SANTANA, Augustín. Antropologia do Turismo. Analogias, Encontros e Relações. São Paulo: Aleph, 2009.

SANSOLO, D.G. Políticas e planejamento do turismo na Amazônia. Caderno Virtual de Turismo. Rio de Janeiro, v. 13, n. 1, abr. 2013, p.105-119.

SCHAFER, E.; CHOI, Y. Forging nature-based tourism policy issues. A case study in Pennsylvania. Tourism Management, v. 27, 2006, p. 615-628.

SOLHA, K. T. Órgãos públicos estaduais e o desenvolvimento do turismo no Brasil. Escola de Comunicação e Artes da Universidade de São Paulo. São Paulo/SP: USP, 2004. (Tese de Doutorado).

STEVENSON, N.; AIREY, D.; MILLER, G. Tourism policy making: The policymakers'perspective. Annals of Tourism Research, v. 35, n. 33, 2008, p. 732-750.

TORRES DELGADO, A; LÓPEZ PALOMEQUE, F. The growth and spread of sustainable tourism: The contribution of institutional initiatives to tourism policy. Tourism Management Perspectives, v. 4, 2012, p. 1-10. 